12.1

\title{
Вклад газов остаточной атмосферы в поток коллективно ускоренных протонов в диоде Люса
}

\author{
(C) В.А. Рыжков, Г.Е. Ремнев, И.Н. Пятков, М.В. Журавлев
}

Исследовательская школа фризики высокоэнергетических процессов, Томский политехнический университет, Томск, Россия

E-mail: ryzhkov@tpu.ru

Поступило в Редакцию 10 декабря 2019г.

В окончательной редакции 16 января 2020г.

Принято к публикации 20 января 2020 г.

Вклад газов остаточной атмосферы в поток коллективно ускоренных протонов в диоде Люса определен путем сравнения числа протонов, генерированных анодами, выполненными из полиэтилена и пиронитрида бора. Для определения среднего числа протонов за импульс и их энергии использована радиоактивационная диагностика по ядерным реакциям ${ }^{10} \mathrm{~B}(p, \alpha){ }^{7} \mathrm{Be}$ и ${ }^{12} \mathrm{C}(p, \gamma){ }^{13} \mathrm{~N}$. Установлено, что количество протонов, коллективно ускоренных за счет адсорбции и ионизации паров воды и углеводородов остаточной атмосферы вакуумной камеры на поверхности диэлектрической вставки анода, может быть сравнимо с количеством протонов, образуемых непосредственно из материала диэлектрической вставки анода, изготовленной из полиэтилена.

Ключевые слова: адсорбция, поверхность, поглощение энергии, ионизация, полиэтилен, нитрид бора.

DOI: 10.21883/PJTF.2020.08.49299.18147

В диоде Люса пучок релятивистских электронов, проходя через отверстие полиэтиленовой вставки анода, частично испаряет его поверхность, атомизирует и ионизирует испаренные элементы анодной вставки, в том числе поверхностные загрязнения, в основном представленные водородом и углеродом [1]. Общеизвестно, что поверхность твердых тел, как правило, обогащена газами, адсорбированными из окружающей атмосферы, что, естественно, ставит вопрос о вкладе этих газов в поток коллективно ускоряемых ионов. В работе [2] было показано, что слой поверхностных загрязнений твердой мишени, очищаемой мощным импульсным ионным пучком, частично восстанавливается в течение нескольких секунд после обработки, при этом содержание водорода, углерода и кислорода на обработанной импульсным ионным пучком поверхности, в частности, высокочистого алюминия достигает значений $0.01-0.5 \mu \mathrm{g} / \mathrm{cm}^{2}[3,4]$. Несложно определить, что $0.01 \mu \mathrm{g}$ водорода соответствует $6 \cdot 10^{15}$ его атомов, что на полтора порядка перекрывает верхние значения числа протонов, коллективно ускоряемых за один импульс (около $10^{14}$ ) в обычных режимах. Отсюда возникает еще один очевидный вопрос: а нужно ли вообще использовать в качестве источника протонов импульсное испарение материала диэлектрической вставки анода за счет поверхностного пробоя, неизбежно приводящее к его значительной эрозии и изменению геометрии диодного промежутка?

Прямой ответ на поставленные вопросы позволяет дать сравнение выходов коллективно ускоренных протонов в одинаковой геометрии диода Люса с анодами из материалов, содержащих и не содержащих водород. В настоящей работе проведено сравнение потоков протонов при использовании анодных вставок, выполненных из полиэтилена (ПЭ) и пластин пиронитрида бора. В последнем случае водород может присутствовать лишь в адсорбированном поверхностью анода состоянии, тогда как сам пиронитрид бора характеризуется очень высокой удельной энергией сублимации (30-40 J/mg), практически исключающей эрозию его поверхности под воздействием мощного импульса релятивистских электронов и поверхностного пробоя и тем самым гарантирующей долговечность анода.

Анодные вставки были выполнены в виде шайб толщиной $3 \mathrm{~mm}$ с внутренним диаметром $12 \mathrm{~mm}$. В исследуемой геометрии диода Люса торец цилиндрического вольфрамового катода диаметром $4 \mathrm{~mm}$ и длиной $15 \mathrm{~mm}$ был выставлен аксиально заподлицо с внешним торцом анодной вставки. В такой геометрии диод Люса способен генерировать электронные пучки с длительностью $90 \mathrm{~ns}$, током до $30 \mathrm{kA}$ при напряжении $250 \mathrm{kV}$ с интервалом повторения 4-5 s. Пучок коллективно ускоренных ионов перехватывался пластинами карбида бора $\mathrm{B}_{4} \mathrm{C}$ размером $5 \times 5 \times 0.5 \mathrm{~cm}$, размещенными соосно с катодом и анодом на расстоянии $9 \mathrm{~cm}$ от внешнего торца анодной вставки. Сразу после облучения сериями из трех, десяти и пятидесяти импульсов рабочая камера ускорителя ТЕМП-4 вскрывалась для транспортировки облученной мишени на торец коаксиального детектора из высокочистого германия (Canberra) в свинцовой защите для регистрации протонно-индуцированной $\gamma$-активности ${ }^{7} \mathrm{Be}$ $\left(T_{1 / 2}=53.12\right.$ дня) и ${ }^{13} \mathrm{~N}(9.965 \mathrm{~min})$ в пиках с энергией 477.6 и $511 \mathrm{keV}$ соответственно согласно радиоактивационной методике диагностики коллективно ускоренных протонов, описанной в [5].

В таблице приведены суммарные данные по сравнению энергии и выхода протонов из анодных вставок, 
Суммарные результаты

\begin{tabular}{c|c|c|c|c|c|c}
\hline $\begin{array}{c}\text { № } \\
\text { п/п }\end{array}$ & $\begin{array}{c}\text { Материал } \\
\text { анода }\end{array}$ & $\begin{array}{c}\text { Число } \\
\text { импульсов } \\
\text { в серии }\end{array}$ & $\begin{array}{c}\text { Энергия } \\
\text { протонов, } \\
\mathrm{keV}\end{array}$ & $\begin{array}{c}\text { Число } \\
\text { протонов, } \\
10^{13} / \mathrm{imp}\end{array}$ & $\begin{array}{c}\text { Доля } \\
\text { ВN к ПЭ, } \\
\%\end{array}$ & $\begin{array}{c}\text { Убыль веса } \\
\text { мишени, } \\
\mathrm{mg} /\left(\mathrm{cm}{ }^{2} \cdot \mathrm{imp}\right)\end{array}$ \\
\hline 1 & $\mathrm{BN}$ & 3 & 750 & 3.93 & 78 & 0.133 \\
2 & $\mathrm{BN}$ & 10 & 600 & 2.61 & 60 & 0.193 \\
3 & $\mathrm{BN}$ & 50 & 625 & 1.28 & 45 & 0.107 \\
4 & ПЭ & 3 & 650 & 5.05 & - & 0.467 \\
5 & ПЭ & 10 & 625 & 4.33 & - & 0.485 \\
6 & ПЭ & 50 & 620 & 2.85 & & 0.391
\end{tabular}

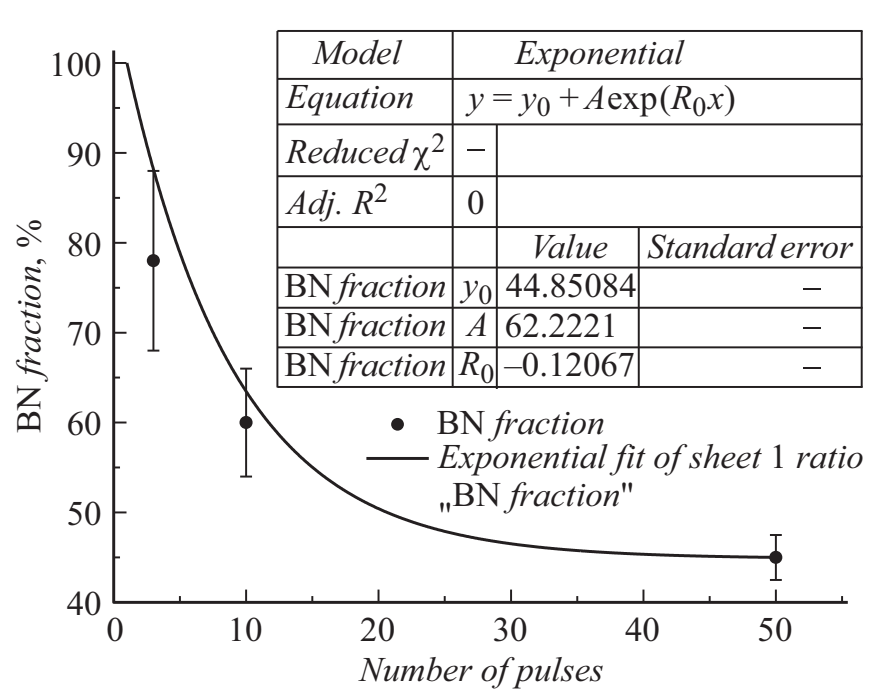

Сравнение отношения выхода протонов из BN-анода с экспонентой.

изготовленных из ПЭ и $\mathrm{BN}$, для приведенных выше серий импульсов. Из таблицы и рисунка видно, что отношение среднего числа протонов, коллективно ускоренных с использованием анодной вставки из нитрида бора, к числу протонов из полиэтиленовой вставки для серии из трех последовательных импульсов составляет $78 \%$ и спадает примерно экспоненциально для большего числа импульсов в серии, составляя лишь $45 \%$ для серий по пятьдесят импульсов. Экстраполяция зависимости на одиночные импульсы (они же первые импульсы серии) показывает, что это отношение может быть близко к $100 \%$. Подобная зависимость указывает на то, что пауза в 4-5 s между импульсами, возможно, недостаточна для восстановления максимально возможного количества водородсодержащих газов и паров воды, сорбируемых поверхностью анода из пиронитрида бора при используемой величине давления остаточного газа $\left(10^{-5} \mathrm{~mm}\right.$ $\mathrm{Hg})$.

Расчеты величины поглощенной энергии коллективно ускоренных ионов в мишень $\mathrm{B}_{4} \mathrm{C}$ показывают, что сублимация мишени возможна лишь за счет поглощения тяжелоионного, в основном углеродного, компонента. Удельная убыль веса мишеней за один импульс состави- ла $144 \pm 44 \mathrm{ng} / \mathrm{cm}^{2}$ для анодной вставки из $\mathrm{BN}$ против $448 \pm 50 \mathrm{ng} / \mathrm{cm}^{2}$ для полиэтиленовой анодной вставки, что указывает на кратно бо́льшую долю коллективно ускоренных ионов углерода в случае полиэтиленовой анодной вставкой, чем при использовании вставки из нитрида бора. Этим, в частности, может быть обусловлен факт ускорения протонов до существенно бо́льших энергий в случае BN-анода в коротких сериях из трех импульсов, где максимально проявляется вклад самого первого импульса серий. Поскольку энергия, переносимая электронным пучком, имеет конкретную величину, бо́льшая примесь тяжелых ионов, вовлекаемых в процесс коллективного ускорения, будет отнимать и бо́льшую долю энергии, переносимой электронным пучком, что в результате снизит общую энергию коллективно ускоренных протонов при ускорении с анодами, углеводородный материал которых легко сублимирует, атомизируется и ионизируется. Для полиэтиленового анода вклад адсорбированных газов не имеет большого значения в силу более низких удельных энергозатрат на плазмообразование самого материала анода. При этом число атомов углерода и, как следствие, ионов углерода задается стехиометрией полиэтилена: $\mathrm{H} / \mathrm{C}=2: 1$.

Для первого импульса в серии количество адсорбированных поверхностью $\mathrm{BN}$-анода газов из остаточной атмосферы максимальное, но это количество водородсодержащих примесей заведомо ниже предельного числа атомов, которые могут быть ионизированы и эффективно ускорены в данной геометрии диода Люса, поскольку для серии из трех импульсов обнаруживается заметно бо́льшая средняя энергия протонов и максимальное их число в отдельном импульсе. С другой стороны, полиэтиленовая анодная вставка может образовывать излишнее количество ионов, особенно тяжелых, что может быть в ущерб ускорению легких ионов (протонов или дейтронов). По этой причине, на наш взгляд, более эффективным может быть коллективное ускорение с анодными вставками из материала с высокой эрозионной стойкостью, например такого, как пиронитрид бора. Недостаточно быстрое восполнение адсорбируемых его поверхностью газов может быть достигнуто за счет корректировки химического состава и повышения давления остаточной атмосферы рабочей камеры ускорителя. Аль- 
тернативным подходом может быть использование в качестве материала анода жаропрочных диэлектрических материалов с более высокой сорбционной способностью.

Таким образом, к очевидным преимуществам использования анодных вставок из диэлектрических материалов с высокой эрозионной стойкостью, например пиронитрида бора, кроме уже отмеченного увеличения ресурса подобного анода можно отнести возможность значительного снижения доли коллективно ускоренных тяжелых ионов: углерода и кислорода. Это крайне важно при получении короткоживущих радионуклидов для медицинских целей, поскольку позволяет избежать импульсного испарения материала поверхности мишени и, как следствие, потерь радионуклидов, максимум активности которых нередко приходится именно на приповерхностный слой.

\section{Финансирование работы}

Работа выполнена при финансовой поддержке гранта Российского научного фонда (грант 17-19-01442).

\section{Конфликт интересов}

Авторы заявляют, что у них нет конфликта интересов.

\section{Список литературы}

[1] Luce J.S., Sahlin H., Crites N.R. // IEEE Trans. Nucl. Sci. 1973. V. 20. N 3. P. $336-340$.

[2] Remnev G.E., Isakov I.F., Opekunov M.S., Matvienko V.M., Ryzhkov V.A., Struts V.K., Grushin I.I., Zakoutayev A.N., Potyomkin A.V., Tarbokov V.A., Pushkaryov A.N., Kutuzov V.L., Ovsyannikov M.Yu. // Surf. Coat. Technol. 1999. V. 114. N 2-3. P. 206-212.

[3] Stinnett R.W., Maenchen J.E., Renk T.J., Struwe K.W., Campbell M.M. // Proc. of the 11th Int. Conf. on high power particle beams (BEAMS'96). Prague, 1996. V. II. P3-42. P. 882-885.

[4] Ziegler J.F., Wu C.P., Williams P., White C.W., Terreault B., Schertzer B.M., Schulte R.L., Schneid E.J., Magee C.W., Ligeon E., L'Ecuyer J.L., Lanford W.A., Kuehne F.J., Kamyshovski E.A., Hofer W.O., Guivarch A., Filleux C.H., Deline V.R., Contego T., Cohen B.L., Clark G.J., Chu W.K., Brassard C., Blewer R.S., Behrisch R., Appleton B.R., Allred D.D. Profiling hydrogen in materials using ion beams. IBM Report N 8-1. IBM Research Division, 1977. RC6663 (\#28655). $36 \mathrm{p}$.

[5] Рыжкков В.А., Ремнев Г.Е., Журавлев М.В., Пятков И.Н., Лопатин В.С. // Письма в ЖТФ. 2019. Т. 45. В. 14. С. 3133. 